\title{
INTRACARDIAC METASTASIS FROM TESTICULAR TERATOMA
}

BY

\author{
P. R. FLEMING AND W. J. HARRISON \\ From Westminster Medical School and Westminster Hospital, London S.W. 1
}

Emanuel and Lloyd (1962) have recently re-emphasized the close similarity between the clinical picture of right atrial myxoma and that of constrictive pericarditis. In the case presented here this same clinical picture was produced acutely by a metastasis from a testicular teratoma within the cavities of the right atrium and ventricle.

\section{Case Report}

A man aged 36 had a left orchidectomy for teratoma in November 1960, and was referred to the Radiotherapy Department of Westminster Hospital on December 8, 1960. Between that date and January 19, 1961, he was given radiotherapy to the abdomen. Thereafter he remained in good health until June 1961, when he developed pleuritic pain in the front of the left side of the chest and, later, similar pains in the right axilla and both scapular regions. There was slight hæmoptysis at this time and he was very dyspnœic at the onset of the pain but this rapidly subsided. Chest radiograph showed no significant abnormality. In October 1961, he once again noticed dyspnœa on exertion which gradually increased in severity. There was no abnormality on physical examination. Chest radiograph showed a small right pleural effusion. There were also a few tiny opacities in both lung fields but tomography of the whole chest showed no evidence of metastases nor of hilar gland enlargement. Hogben and Friedman tests were negative. By the end of January, chest radiograph showed that the pleural effusion had resolved but there had been a small increase in heart size with prominence of the right atrium and superior vena cava.

On February 11, 1962, he was admitted complaining of an acute onset of very severe dyspnœa while walking briskly one week previously. He had become cyanosed and had almost lost consciousness. Since then he had been breathless at rest. He had a slight cough but there had been no further hæmoptysis. $\mathrm{He}$ also had poorly localized discomfort in the chest on deep inspiration. On examination he was well built, obviously dyspnœic at rest but able to lie flat without discomfort. There was no clubbing of the fingers or toes and no lymph nodes were palpable. The pulse was markedly paradoxical, and the blood pressure was $120 / 80 \mathrm{~mm}$. $\mathrm{Hg}$. The venous pressure was raised $8-10 \mathrm{~cm}$. above the sternal angle, the " $y$ " descent was very steep, and Kussmaul's sign was positive. The apex beat was impalpable but the cardiac dullness was normal on percussion. At the lower left sternal edge a loud third heart sound was heard and also a "scratchy" murmur beginning about the middle of systole and extending up to but not, at this time, beyond the second sound; this murmur was much louder on expiration. The liver edge was three finger breadths below the costal margin but there was no œdema. There was no abnormality on examination of the lungs, abdomen, or central nervous system. There was no change in the chest radiograph and fluoroscopy showed cardiac pulsations of normal amplitude. The electrocardiogram was normal. Mantoux test was negative at $1 / 100$ dilution.

The dyspnœa progressively increased in severity, and ten days after admission he complained of a dull pain in the left submammary region, radiating down the radial side of the left arm to the thumb. By this time he was intermittently drowsy and confused and the murmur now extended into the first third of diastole; a note was made that it sounded "more like a friction rub". On February 26 slight sacral œdema appeared and, by next day, he was extremely dyspnœic and cyanosed. The œdema spread to involve the abdominal wall and widespread petechiæ appeared, particularly over the shoulders. The heart sounds became faint and, though pericardial effusion was not thought likely, a pericardial paracentesis was attempted. No fluid was obtained and the patient died later the same day. 


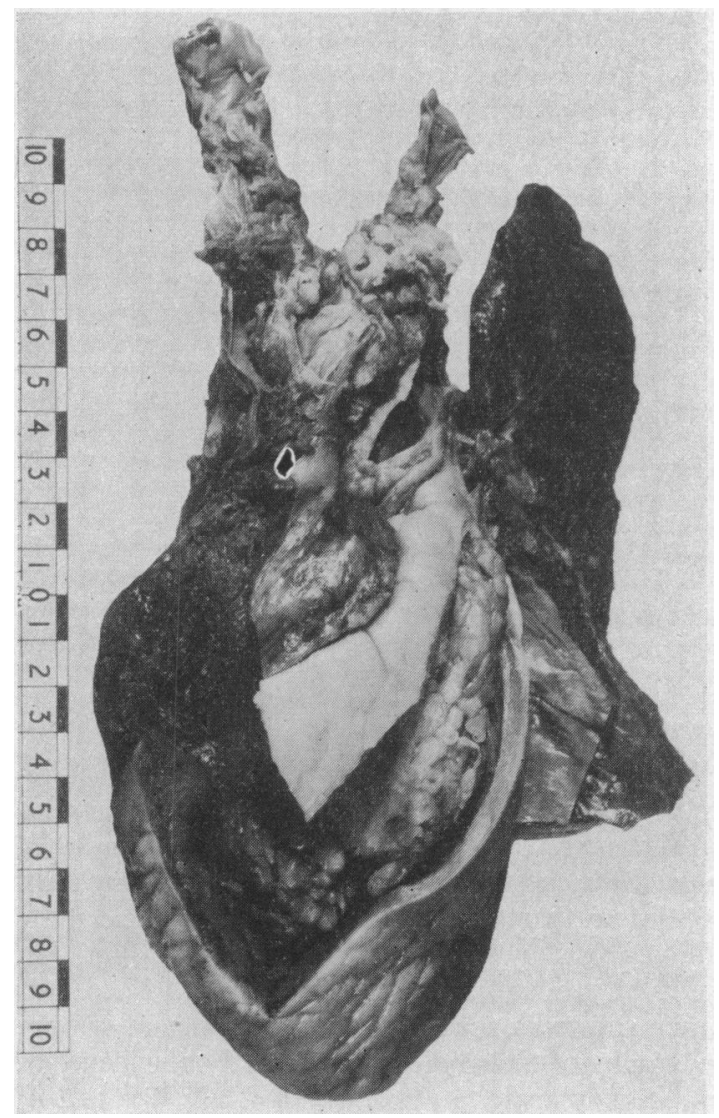

FIG. 1.-Intravascular tumour extending in continuity from the proximal ends of the internal jugular and innominate veins to the pulmonary arteries.

Necropsy. Numerous lymph nodes of the lower deep cervical groups on either side and those clustered around the innominate veins were enlarged to $1 \cdot 0-1 \cdot 5 \mathrm{~cm}$. in diameter by hæmorrhagic tumour deposits. Invaded nodes were also present in the posterior mediastinum and a few of the aortic group were involved. The thoracic duct and cisterna chyli could not be identified. The innominate veins and last 3-5 cm. of the internal jugular and subclavian veins were filled by loculated, myxomatous tumour tissue resembling white grapes which extended through the superior vena cava and filled the right atrium and ventricle, pulmonary trunk, right and left pulmonary arteries, and their branches (Fig. 1). On sectioning the lungs gelatinous tumour bulged from small pulmonary arteries in all lobes (Fig. 2). Tumour tissue thus formed a continuous cast of the superior vena cava and its main tributaries, the right heart, and the pulmonary arterial tree. Much of the growth lay free within the heart and vessels leaving a narrow slit between tumour and vascular endothelium for the passage of blood. The endocardium of the right atrium and tricuspid valve showed small areas of roughening, and, though in both atrium and ventricle tumour was lightly adherent to the endocardial surface at some points, there was no evidence of invasion of the walls of heart or vessels by the enclosed growth.

The right ventricle was dilated but not hypertrophied. The pulmonary veins, left atrium, and ventricle were normal, the cardiac valves healthy (apart from the roughening on the tricuspid valve), and the coronary arteries free of atheroma. The myocardium was of normal appearance. The inferior vena cava and its tributaries were free of growth.

There was a straw-coloured effusion of $50 \mathrm{ml}$. in the pericardial sac and loculated effusions of $\frac{1}{2}-1$ litre were present in each pleural cavity. In the lungs tumour was confined to the pulmonary arteries. There was approximately a litre of clear ascitic fluid in the peritoneal cavity. The serous surfaces all showed numerous petechiæ but no evidence of tumour. The liver was enlarged (2280 g.) and showed chronic venous congestion. Some small secondary deposits were found in the capsule of the left adrenal. Other organs were normal.

The histology of the primary testicular tumour was typical of a teratoma. Cartilage, bone, and epithelium of intestinal and respiratory type were present together with undifferentiated elements. Trophoblastic tissue was not seen. Sections from the necropsy material showed that the intravascular tumour locules were coated with fibrin and consisted of scattered glandular structures lying in abundant myxomatous tissue. In the right atrium and on the tricuspid valve there were small endocardial deposits of fibrin but there was no cellular reaction. Tumour was found in pulmonary arteries down to $400 \mu$ in diameter and areas of infarction were associated with thrombosis of some smaller vessels. Around arterioles and capillaries there were numerous giant cell systems, probably a reaction to tumour products (Gresham and Ackerley, 1958). There was no caseation and acid-fast bacilli could not be found. A notable feature in sections of the cervical lymph nodes was the invasion of innumerable adjacent veins.

\section{Discussion}

Much the commonest primary intracavitary tumour of the chambers of the right side of the heart is atrial myxoma, but fibrosarcoma (Cope, 1957) and hæmangio-endotheliosarcoma (Cheng and 


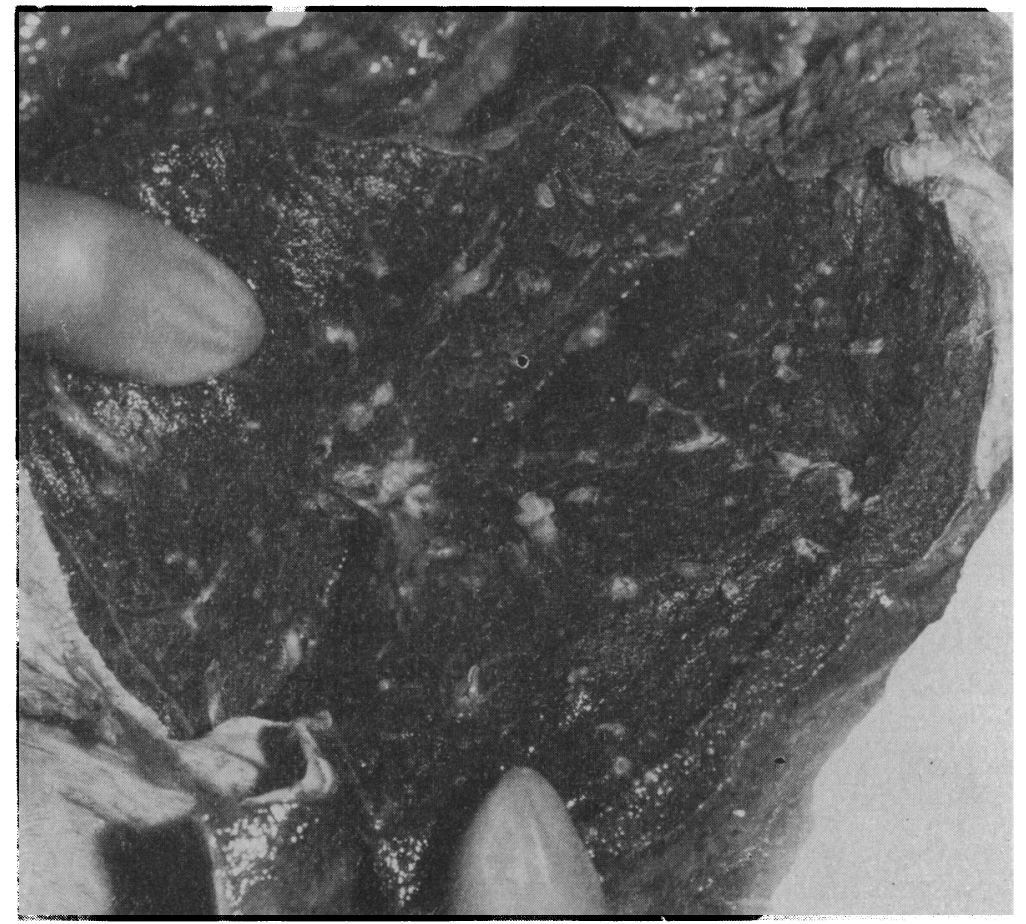

FIG. 2.-The cut surface of a lung showing blebs of tumour bulging from small pulmonary arteries.

Sutton, 1955) have also been described. In addition, invasion by tumour of the great veins with extension to the right atrium and ventricle has also been described. This is most frequently seen in carcinoma of the kidney (Polayes and Taft, 1931), sarcoma, especially chondrosarcoma (Fry and Shattock, 1926; Kósa, 1929), and testicular teratoma, but not seminoma (Dew, 1925). Direct extension of the growth into the pulmonary artery and its branches is uncommon, but there are two reported cases of comparable severity. It is noteworthy that one of these was a case of testicular teratoma (Herzog, 1917). A 35-year-old man presented with swelling of the right testis. Orchidectomy was performed but he died four months later with extensive cervical and abdominal metastases. No cardiovascular or respiratory symptoms are recorded. At necropsy there was invasion of the right pampiniform plexus, para-aortic lymph nodes, inferior vena cava, right atrium, ventricle, and pulmonary arteries. Kósa (1929) described the case of a girl of 13 with chondrosarcoma of the right femur which invaded the femoral vein and extended in continuity through the inferior vena cava, right heart, and into the smallest arteries of both lower lobes while involving segmental branches in the other lobes.

In the present case the route of tumour dissemination is of some interest. The first stage was evidently spread to the aortic lymph nodes. Though the cisterna chyli and thoracic duct could not be demonstrated they are the most likely path of invasion of the cervical and innominate nodes. Tumour may well have invaded the great veins directly from the thoracic duct. However, numerous small veins packed with growth were found histologically in the vicinity of the invaded cervical lymph nodes. These vessels must have drained more or less directly into the great veins around which the lymph nodes were clustered, providing ready access of tumour to the venous system. Though by the time of death tumour formed a continuous column from these veins to the smaller pulmonary arteries, suggesting progressive intravascular growth, multiple small tumour emboli probably played a part in producing the final picture. Indeed, the sudden onset of dyspnœa in February 1962 suggests an episode of embolism. 
Some of the physical signs found in this patient were present in many of the recorded cases of intracavity tumours of the right heart and, in particular, the case of myxoma described by Emanuel and Lloyd (1962) is almost identical. Gross pulsus paradoxus was present in their patient, and this was also noted by Frankenfeld, Waters, and Steiner (1960), in a patient with myxomata of both atria, and by Cheng and Sutton (1955) in their case of right atrial hæmangio-endotheliosarcoma. The venous pressure was high in many of the recorded cases, but only Emanuel and Lloyd (1962) mention the sharp " $y$ " descent and positive Kussmaul's sign.

The most interesting physical sign was the murmur extending from mid-systole into the first third of diastole and interpreted as a friction rub. Emanuel and Lloyd (1962) described a very similar bruit, and a friction rub was heard by Frankenfeld et al. (1960), Ellis, Mankin, and Burchell (1958), and Morrissey et al. (1963) in cases of right atrial myxoma and by Cope (1957) in a patient with fibrosarcoma of the right atrium. At necropsy in Cope's case there was roughening of the tricuspid valve and endocardium of the right atrium similar to that seen in our patient; this was also noted by Kendall and Symonds (1952) in a case of right atrial myxoma but no friction rub was heard in their case. It seems that this physical sign is not uncommon in the presence of myxoma or other intracavitary tumours of the right atrium and ventricle. In view of the facts that the tumour and the atrial or ventricular endocardium are in physical contact and that fibrin deposition on the relevant areas of endocardium has been found in some cases, it seems appropriate to describe this bruit as an "endocardial friction rub".

\section{Summary}

A patient with metastatic testicular teratoma is described in whom there was massive invasion of the chambers of the right heart and pulmonary artery. This produced the clinical picture of acute constrictive pericarditis and, in addition, a characteristic continuous bruit which has been designated an "endocardial friction rub".

We are grateful to Professor A. D. Morgan for valuable criticism of the manuscript and to Dr. K. Lewin for translating the German references. We are also indebted to the staff of the Department of Medical Photography and Illustration for the figures.

\section{References}

Cheng, T. O., and Sutton, D. C. (1955). Primary hemangioendotheliosarcoma of heart, diagnosed by angiocardiography. Circulation, 11, 456.

Cope, S. (1957). Fibrosarcoma of right auricle. Brit. med. J., 1, 987.

Dew, H. R. (1925). Malignant Disease of the Testicle. Lewis, London.

Ellis, F. H., Mankin, H. T., and Burchell, H. B. (1958). Myxoma of the atrium: successful surgical treatment in two cases. Med. Clin. N. Amer., 42, 1087.

Emanuel, R. W., and Lloyd, W. E. (1962). Right atrial myxoma mistaken for constrictive pericarditis. Brit. Heart J., 24, 796.

Frankenfeld, R. H., Waters, C. H., and Steiner, R. C. (1960). Bilateral myxomas of the heart. Ann. intern. Med., $53,827$.

Fry, H. J. B., and Shattock, C. E. (1926). Sarcomatous permeation of the inferior vena cava and right side of the heart. Brit. J. Surg., 14, 337.

Gresham, G. A., and Ackerley, A. G. (1958). Giant cell granulomata in regional lymph nodes of carcinoma. J. clin. Path., 11, 244.

Herzog, G. (1917). Uber ein metastasierendes, malignes Hodenteratom und seine Histogenese. Beitr. path. Anat., 63, 755 .

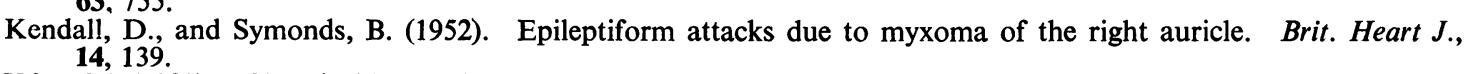

Kósa, M. (1929). Chondroblastom in der venösen Blutbahn. Virchows Arch. path. Anat., $272,166$.

Morrissey, J. F., Campeti, F. L., Mahoney, E. B., and Yu, P. N. (1963). Right atrial myxoma. Report of two cases and review of the literature. Amer. Heart J., 66, 4.

Polayes, S. H., and Taft, H. (1931). A case of hypernephroma with tumor thrombosis of vena cava and heart. Amer. J. Path., 7, 63. 